\title{
LA PREDICCIÓN DEL FRACASO EMPRESARIAL EN EL SECTOR HOTELERO
}

\author{
Antonio Álvarez-Ferrer* \\ Universitat Rovira i Virgili. Tarragona \\ https://orcid.org/0000-0003-1136-9412 \\ Fernando Campa-Planas* \\ Universitat Rovira i Virgili. Tarragona \\ https://orcid.org/0000-0001-7175-6698
}

\section{RESUMEN}

El objetivo de este estudio es analizar las empresas concursadas del sector hotelero en España,desde el año 2007 hasta el 2017, empleando fórmulas de predicción del fracaso empresarial que sean aplicables a este tipo de actividad económica. La elaboración de modelos de predicción de la insolvencia se inició en Estados Unidos con los trabajos pioneros de Beaver y Altman en la década de los años sesenta. Después de años de mejoras metodológicas y de estudios aplicados a diferentes sectores, no se ha conseguido unificar un método por la comunidad científica, por lo que para la realización de este estudio se utilizarán las fórmulas Z de Altman de los años 1968 y 1983 y se compararán con la fórmula de Amat et al. de 2017. Los dos métodos de Z-Score aplicados a las empresas del sector hotelero en concurso de acreedores en España nos muestran un alto porcentaje de coincidencias en los ejercicios previos a la declaración oficial del concurso, siendo el de Altman el que obtiene una mejor aproximación al número total de empresas concursadas.

Palabras clave: Fracaso empresarial; concurso de acreedores; fórmula Z; sector hotelero; predicción del fracaso empresarial.

\section{The prediction of business failure in the hospitality business}

\section{ABSTRACT}

The main goal of this study is to carry out an analysis about the bankrupt of companies in the hospitality sector in Spain from 2007 to 2017, applying prediction formulas of business

Fecha de recepción: 12 de septiembre de 2018 .

Fecha de aceptación: 10 de febrero de 2019.

* Departamento de Gestión de Empresas. Universitat Rovira i Virgili. Avda. de la Universitat, 1.43204 Reus.TARRAGONA (España).E-mail: antonio.alvarez@urv.cat, fernando.campa@urv.cat 
failure. The development of models for insolvency prediction began in the United States with the pioneering works of Beaver and Altman in the 1960s. After years of methodological improvements and studies applied to different sectors, it has not been possible to unify amethod applicable bythe Academia. Therefore, the realization of this study has been using the formula Z of Altmanof 1968 and1983and compare them with the formula Z of Amat et al. of 2017. The two methods of Z-Score applied to the companies of the hospitality sector in Spain in bankruptcy process show us a highly percentage of matches in the exercises before the official bankruptcy process, being Altman the one that obtains a better approach to the total number of bankruptcy companies.

Keywords: Business failure; bankruptcy Process; Z-Scoring; hospitality; business failure prediction.

\section{INTRODUCCIÓN}

Con el presente estudio se pretende llevar a cabo un análisis económico financiero de determinadas empresas del sector hotelero al objeto de determinar la evolución de las empresas concursadas de forma longitudinal, siendo necesario esteanálisis para observar en las empresas concursadas la información correspondiente a aspectos como liquidez, endeudamiento, rentabilidad económica, etc.Para ello será necesario recopilar datos del sector hotelero, estableciéndose el año 2007 como punto de inicio del estudio y el 2017 como punto final. Dicho periodo nos permitirá tener una amplia visión de qué variables pueden tener una mayor influencia paradescribir los aspectos clave que caracterizan a las empresas concursadas y, a su vez, se contrastarán las mismas variables para validar, o no, si los aspectos claves detectados pueden servirnos para categorizar esta tipología de empresas.

El ámbito de actuación del presente trabajo será el sector hotelero en España. Las empresas de las que se han obtenido sus datos y que se encuentran oficialmente en proceso concursal, se han conseguido a través de la información disponible en la base de datos SABI.

Para concluir esta introducción, sólo remarcar que la importancia de este estudio viene dada en comprobar si los dos métodos que se van a proponer para predecir la insolvencia hubieran sido capaces de detectar las empresas del sector hotelero en España que, oficialmente según SABI, estaban en concurso de acreedores en el período analizado.

\section{MARCO CONCEPTUAL}

En este apartadose analizan conceptos como el fracaso económico, el fracaso financiero y el fracaso jurídico, una revisión de literatura sobre propuestas de fórmulas Z para predecir el fracaso empresarial y las propuestas metodológicas previas para la realización de la predicción del fracaso empresarial en el sector hotelero objeto de este trabajo.

Para la obtención de la información necesaria para elaborar este trabajo se ha realizado una búsqueda de artículos relacionados con el tema objeto de discusión en la base de datos SCOPUS(2018), otra búsqueda de datos cuantitativos en el Instituto Nacional de 
Estadística (INE, 2018) y el trabajo de campo con las empresas concursadas mediante la base de datos SABI (2018).

\subsection{Estado de la cuestión}

Como cuestión previa es importante señalar que existen tres estados distintos de fracaso que se derivan de la situación económico-financiera de las empresas y que nos permitirán observar mejor las diferencias existentes entre organizaciones saneadas y no saneadas (Gazengel y Thomas, 1992):

- Fracaso económico: es el caso de una empresa que estructuralmente no es rentable y que genera de forma cíclica más gastosque ingresos.

- Fracaso financiero: es el caso de una empresa que mantiene de forma constante tensiones de liquidez provocadas por desajustes en su tesorería y que le generan desequilibrios en su estructura económica y financiera.

- Fracaso jurídico: es el reconocimiento legal del fracaso financiero. Se trata de la constatación jurídica de la insolvencia.

Una revisión de la literatura nos revela poca investigación desarrollada en el campo del bankruptcy en el sector hotelero y si buscamos entre el vasto número de estudios desde el año 1965, muy pocos de ellos fueron aplicados a este sector (Diakomihalis, 2012).

Veamos, a continuación, algunas aportaciones de diversosautores sobre aspectos que permiten llevar a una empresa a salir del estado en el que se encuentra cuando está inmersa en un proceso concursal o, por el contrario, qué factores facilitan que una empresa en concurso acabe en liquidación, siendo esta afirmación la que engloba mayor número de empresas. También analizaremos a dos autores que han realizado propuestas para prevenir o detectar la situación de quiebra antes de que se produzca, como son Altman $(1968,1983)$ y Amat et al. (2017). Se han seleccionado a estos dos autores para poder comparar sus fórmulas de predicción desarrolladas en épocas distantes y que fueron diseñadas para sectores distintosdonde las empresas podían tener un comportamiento diferente si se trataba de empresas pri vadas,públicas,manufactureras o de servicios, en el caso de Altman, o deentidades de crédito y empresas de servicios en el caso de Amat et al.Con todo ello, se puede asentir que ambas fórmulas pueden ser aplicadas al sector hotelero si tenemos en consideración que el mismo forma parte del sector servicios. También se deja constancia de las aportaciones realizadas por Altman en 2017 al revisar sus propias fórmulas a las que añadió otras variables como el tamaño, el país, el año de la quiebra y la antigüedad de la empresa. Con todo ello, queremos verificar si son válidas para el sector hotelero en España y cuál es su nivel de acierto o de aproximación en la predicción de las empresas concursadas.

Existen algunos autores que han hecho investigacionesdecómo se puede predecir en el sector hotelero la situación de la bankruptcy. El primer autor es Vargas (2015), el cual realiza un estudio para valorar la capacidad de predecir la insolvencia en el sector empresarial en Costa Rica comparando los modelos de Beaver (1966), Ohlson (1980) y Altman $(1968,1983)$. Pues bien, los resultados obtenidos en el análisis de un hotel turístico entre los años 2006 y 2009 muestran que el modelo de Altman detectó la situación en el 100\% de los ejercicios analizados, mientras que el modelo de Ohlson y Beaver lo hicieron en el $50 \%$. El mismo autor hizo la misma comparación en una aerolínea y el modelo de Altman 
volvió a conseguir el 100\% de los 3 años analizados (1994 a 1996) mientras que Beaver predijo el $66 \%$ y Ohlson el $33 \%$.

Otro autor que ha analizado la validez del método Altman en la predicción del fracaso empresarial en el sector hotelero en Grecia es Diakomihalis (2012) y, para ello, ha utilizado las 3 versiones del modelo Altman para evaluar empresas hoteleras. Los resultados obtenidos de modelo $\mathrm{Z}_{1}$ consigue una exactitud del $88,24 \%$, el modelo $\mathrm{Z}_{2}$ alcanza el $83,33 \%$ de acierto y el modelo $\mathrm{Z}_{3}$ el $80 \%$. El propio autor destaca como limitación a su investigación que existen factores como la dimensión del hotel, su ubicación geográfica, la estacionalidad, categoría del hotel, etc. que pueden hacer variar los resultados de diferentes empresas hoteleras. La conclusión general a la que llegó Diakomihalis es que con los resultados obtenidos con el modelo Altman se puede considerar la previsión de bankruptcy con considerable éxito para las empresas hoteleras en Grecia.

En contraposición a alguna de las variables que Diakomihalis denuncia como limitación a su estudio, el propio Altman (2017) indica que factores como la actividad económica o tipo de industria, la antigüedad o el país donde se ubique la empresa tienen un efecto marginal en la detecciónde bankruptcy, en cambio considera que sí tienen una especial relevancia variables como la medida (size)de la empresa y el año en el que se produce la situación de bankruptcy. Cabe destacar que Altman en este estudio incluyó 7 tipos distintos de industrias entre las que se encontrabaun grupo que conteníahoteles y restaurantes.

$\mathrm{Gu}$ and Gao (2000) llevaron a cabo un estudio para detectar el potencialbankruptcy en el sector hotelero mediante el análisis discriminante múltiple (MDA) como técnica estadística que les permitió el estudio de las diferencias entre 2 o más grupos de objetos respecto a algunas variables simultáneamente. Obtuvieron una exactitud del 93\%, pero se limitaron a analizar el año previo a la situación de bankruptcy. Destaca en su estudio como limitación la pequeña muestra de tan solo 14 empresas seleccionadas para llevar a cabo el análisis descrito y, por lo tanto, la necesidad de ampliar el estudio a más años de anticipación para la correcta predicción de bankruptcy.

Siguiendo en la línea de trabajos relacionados con el sector hotelero, encontramos el estudio realizado por Vivel-Búa et al. (2015). En él se cuestionan los determinantes de la quiebra de los hoteles españoles y ponen de manifiesto la no existencia empírica de la quiebra hotelera en el contexto español, por lo que eséste uno de los motivos de la realización del presente trabajo.Los mismos autores describen que las empresas quebradas analizadas presentan un menor tamaño y poca antigüedad, valores más bajos de rentabilidad, liquidez, actividad y porcentaje de fondos propios sobre activo corriente. Por otro lado, presentan mayores valores en las variables de endeudamiento y porcentaje de activo corriente sobre el activo total. Vivel-Búa et al. (2015) obtienen en sus resultados similitudes con trabajos en otros sectores de actividad. Por lo tanto, según dichos autores, la probabilidad de quiebra en la pequeña y mediana empresa hotelera mantiene una relación positiva con el endeudamiento y la estructura económica, y negativa con la rentabilidad, la actividad, la antigüedad y el tamaño. De hecho, las empresas con mayor capacidad de generación de recursos, ylas que obtienen una mejor rentabilidad, de entrada, no estarán expuestas a una situación concursal. La Ley Concursal 22/2003 en su artículo 2 describe como presupuesto objetivo ante la situación de una empresa en concurso de acreedores que ésta se encuentre en estado de insolvencia y que no puede cumplir regularmente 
sus obligaciones exigibles ante proveedores, entidades financieras, Administración, etc. (Álvarez-Ferrer y Campa-Planas, 2018).

Por otro lado, tenemos que un elevado endeudamiento, o lo que es lo mismo, un elevado volumen de recursos ajenos, incrementa la posibilidad de quebrar al no tener capacidad para hacer frente a las obligaciones de pago. Si la empresa tiene una mayor capacidad para generar ingresos se reducirá la probabilidad de quebrar, por lo que la variable actividad está relacionada con una mayor eficiencia.

Con estas afirmaciones, Vivel-Búa et al. (2015), concluyen, en primer lugar, que la literatura académica no ha alcanzado un consenso sobre cuáles son los determinantes de la quiebra empresarial. En segundo lugar, la probabilidad de quiebra empresarial está vinculada a las variables financieras relacionadas con la rentabilidad, endeudamiento, estructura económica y actividad. También consideran como determinantes significativas la antigüedad y el tamaño del hotel.

Otro país en el que se ha realizado un estudio reciente sobre el tema analizado es Jordania. Los autores Jawabrech et al. (2017) utilizaron el método Altman para predecir las situaciones de insolvencia en las compañías del sector hotelero jordano. Con una muestra también pequeña, tan solo 13 empresas hoteleras, llegan a la conclusión de que el método de Altman no es un método lo suficientemente fiable porque ha fallado en una parte importante de las empresas analizadas en su trabajo. Es necesario añadir que las conclusiones que describe este trabajo no parecen del todo concluyentes ya que no se incluyen porcentajes de acierto o aproximación como sí lo han hecho otros autores en estudios similares. Cabe destacar que ha sido el único caso discordante dentro de la revisión de literatura realizada.

En relación con la escasa tasa de éxito del procedimiento concursal en España, García Marí et al. (2018), describen que se debe en gran medida a la ineficacia del propio procedimiento. Posiblemente por un excesivo protagonismo jurídico sobrelos aspectos económicos, por los costes de agencia asociados a los administradores concursales, la cultura empresarial del deudor y los acreedores o la falta de mediosde los juzgados. Dichos autores centran su estudio en demostrar que los costes de agencia asociados a los administradores concursales tienen una incidencia muy alta en la finalización adecuada de los procesos concursales.

Los mismos autores denominan problemas o costes de agencia a los conflictos de intereses entre los accionistas, obligacionistas/acreedores y administradores/directivos, ya que no siempre los objetivos de los tres están alineados. Surge un problema de agencia cuando los directivos de una empresa no hacen aquello que más beneficia a los accionistas o a los acreedores. Esto aplicado al proceso concursal lleva a concluir aGarcía Marí et al. (2018) que el administrador concursal puede tener un interés personal en alargar dicho proceso porque de él depende su remuneración. De hecho, a pesar de las reformas de la Ley Concursal de 2003 (BOE de 10 de julio de 2003)llevadas a cabo en los años 2014 y 2015, el gobierno no ha llevado a cabo la puesta en marcha del fondo de garantía arancelaria para evitar que los administradores concursales se queden sin percibir sucorrespondiente remuneración o, en el mejor de los casos, tengan que esperar a que la empresa liquide sus bienes y, entonces, poder recibir, en su caso, su retribución. 
Los datos aportados por Almazor (2015) reflejan que sólo el 17,72\% de las empresas concursadas en el año 2015, siendo éste el de mayor porcentaje de la serie analizada, presentan directamente la declaración de concurso con la liquidación. Ello significa que sólo el 17,72\% de los concursos son considerados, de entrada, económicamente inviables, por lo que el resto podría potencialmente llegar a buen puerto si el proceso jurídico fuera más ágil. Destaca la información del mismo autor en la que remarca que sólo el 7,48\% de las empresas concursadas concluyen con éxito su proceso y, por lo tanto, el $92,52 \%$ de empresas acaban en liquidación después de pasar entre uno y seis años. Este periodo de tiempo será analizado en este mismo estudio más adelante.

Después de un análisis profundo sobre la importancia del informe de auditoría y su relación en la detección de la insolvencia empresarial, Muñoz-Izquierdo et al . (2017),consideran que el análisis del informe de auditoría en un horizonte mayor de tiempo contribuiría enormemente adetectar problemas de insolvencia que permitiera a los interesados en una compañía actuar con prontitud. Esto es debido a que los informes de auditoría son muy diferentes dependiendo de si son llevados a cabo por una de las denominadas Big4 (Deloitte, PwC, Ernst \& Young y KPMG) o por otra firma de auditoría de menor tamaño (Muñoz-Izquierdo et al., 2017). El hecho de poseer más capacidad y más recursos permite sacar a relucir de forma anticipada los problemas de viabilidad, a pesar de que la solicitud de concurso se haga con retraso, por lo que convierte el informe de auditoría en un instrumento válido para la evaluación del riesgo empresarial.

Concluyen en su trabajoGarcía Marí et al. (2018), que es un hecho que el fracaso de la legislación en los procesos de insolvencia empresarial, con tan escaso porcentaje de empresas que terminan en convenio que les permita continuar su actividad, conlleva graves consecuencias en el tejido empresarial y, además, con un coste muy alto de desempleo y caída de la actividad económica. Por todo ello,infieren que el procedimiento concursal resulta inoperante para lograr que las empresas superen la crisis por el reducido número de empresas que consiguen llegar a convenio. Por último, los mismos autores, ponen de manifiesto que existen diferencias notables en cuanto a la liquidez, solvencia, rentabilidad y tamaño de las empresas que fueron a convenio respecto a las que fueron liquidadas, lo que resulta determinante en la salida exitosa de la situación de insolvencia.

\subsection{Propuestas metodológicas previas}

A continuación, se exponen dos métodos de dos autores de dos épocas distantes. Uno es de Eduard Altman (1968), considerado el precursor de estas técnicas predictivas, y el segundo es de Oriol Amat et al. (2017) que definen una nueva fórmula Z y, al mismo tiempo, concluyen que con menos ratios es posible realizar una predicción de la quiebra de forma apropiada.

Para aportar información sobre la predicción para evitar las quiebras, Altman (1968) realizó un estudio para valorar la calidad del análisis de ratios mediante una técnica analítica aplicada al pronóstico del fracaso empresarial. Para dicho estudio, usó datos de empresas manufactureras y que, oficialmente, se encontraban en una situación de quiebra legal. La técnica estadística que usó Altman fue el Análisis Discriminante Múltiple (MDA) ya que permite clasificar una observación realizada en un grupo definido a priori, 
por ejemplo: quiebra o no quiebra.La muestra inicial para realizar el estudio estaba compuesta por 66 empresas repartidas en dos grupos. Un primer grupo recogía las empresas en quiebra registradas entre los años 1946 y 1965 en los Estados Unidos de América, con unos activos medios de 6,4 millones de dólares. Este grupo estaba caracterizado por su falta de homogeneidaddel tipo de industria y al distinto tamaño. El segundo grupo contenía las empresas que no quebraron en el mismo periodo y que en 1966 todavía existían. En este grupo había empresas manufactureras y se clasificaron por tipo de industria y por tamaño. Las variables utilizadas en este estudio fueron clasificadas en cinco categorías de ratios estándar incluyendo la liquidez, la rentabilidad, el apalancamiento, la solvencia y ratios de actividad.

Con toda esta información Altman diseñó la primera fórmula $\mathrm{Z}$ para la predicción de quiebras e insolvencias en empresas públicas y grandes corporaciones de la siguiente forma:

$$
\begin{aligned}
& \mathrm{Z}_{1}=0,012 \text { (Fondo de Maniobra / Activo) + 0,014 (Beneficios Retenidos / Activo) } \\
& +0,033 \text { (BAII / Activo) + 0,006 (Patrimonio Neto / PN+Pasivo) + 0,999 (Ventas } \\
& \text { / Activo) }
\end{aligned}
$$

La diagnosis de una empresa con la fórmula descrita nos reflejará la probabilidad de insolvencia de acuerdo con los siguientes valores: si $Z<1,81$ la probabilidad de quiebra es alta y si $Z>2,99$ la probabilidad de quiebra es baja.Cuanto mayor sea el valor de $Z$ mejores serán las perspectivas de solvencia de la empresa. Si los valores se encuentran entre $1,81<\mathrm{Z}<2,99$ la empresa estaría en una situación incierta o dudosa.

Las conclusiones a las que llegó Altman con su método fueron las siguientes:

1. Utilizando los datos financieros previos a la quiebra, el modelo obtuvo un acierto de un $95 \%$ del total de las empresas que se declararon en quiebra.

2. Con datos financieros de dos años previos a la quiebra, el acierto obtenido alcanzó un $72 \%$ en un primer grupo y, en un segundo grupo, obtuvo el $94 \%$, por lo que el resultado final fue de un $83 \%$ de fiabilidad.

3. El $65 \%$ de las 66 empresas analizadas presentan pérdidas en los 3 años previos reportados.

4. La predicción a largo plazo, según Altman, no ofrece resultados aceptables y deja constancia en su trabajo que a partir del tercer año la predicción baja a un 48\%, en el cuarto a un $29 \%$ y en el quinto a un $36 \%$.

5. Todos los ratios observados muestran una tendencia a deteriorarse cuanto más se acerca la quiebra.

6. Los cambios más importantes de la mayoría de ratios se producen entre el tercer y segundo año antes de la quiebra.

En el año 1983, Altman hizo una nueva estimación de su método y publicó una segunda fórmula Z para que fuera de aplicación a las empresas privadas (Altman, 1983). Dicha fórmula se determinó de la siguiente forma, en la cual se modificaron los valores, pero no los ratios de la misma: 


\section{$Z_{2}=0,717$ (Fondo de Maniobra / Activo) + 0,847 (Beneficios Retenidos / Activo) + 3,107 (BAII / Activo) + 0,420 (Patrimonio Neto / PN+Pasivo) + 0,998 (Ventas ( Activo)}

En este caso, la diagnosis de una empresa con la fórmula descrita nos reflejará la probabilidad de insolvencia de acuerdo con los siguientes valores: si $Z<1,23$ la probabilidad de quiebra es alta y si $Z>2,90$ la probabilidad de quiebra es baja. Cuanto mayor sea el valor de $\mathrm{Z}$ mejores serán las perspectivas de solvencia de la empresa. Si los valores se encuentran entre $1,23<Z<2,90$ la empresa estaría en una situación incierta o dudosa.

Finalmente, el propio Altman, desarrolló otra nueva fórmula $\mathrm{Z}$ para empresas industriales no manufactureras (Altman, 1983), aplicable a empresas de servicios, y expresada como sigue a continuación, en la cual sí se variaron los ratios a incluir y no solamente los valores de los mismos:

\section{$Z_{3}=6,56$ (Fondo de Maniobra / Activo $)+3,26$ (Beneficios Retenidos / Activo ) + 6,72 (BAII / Activo) + 1,05 (Patrimonio Neto / PN+Pasivo)}

Para esta última fórmula $\mathrm{Z}$ la probabilidad de insolvencia seráde acuerdo con los siguientes valores: si $\mathrm{Z}<1,10$ la probabilidad de quiebra es alta y si $Z>2,60$ la probabilidad de quiebra es baja. Al igual que en las anteriores fórmulas, cuanto mayor sea el valor de $\mathrm{Z}$ mejores serán las perspectivas de solvencia de la empresa. Si los valores se encuentran entre $1,10<Z<2,60$ la empresa estaría en una zona indeterminada.

En base a los resultados obtenidos el modelo de Altman de predicción de insolvenciapuede ser aplicable hasta 2años antes de la quiebra y disminuye sustancialmente a medida que aumenta el tiempo, según el propio autor.

Algunos autores como González Pérez et al. (2004), coinciden con algunospredictores del modelo Z-Score de Altman, en concreto respecto a la capacidad de autofinanciación, la cual es significativa 1y 2 años antes de la quiebra, y la rentabilidad económica, que es determinante1 año antes, lo cual confirma el carácter básico de la rentabilidad en la explicación de la solvencia. Hay que mencionar, además, que el endeudamientoes la variable clave para explicar la quiebra técnica en los 2años previos a la misma.

Los mismos autores, González Pérez et al. (2004), continúan describiendo en su trabajo que las empresas que acumulan un mayor grado de fracaso tienen en común, 2años antes de la quiebra un aumento significativode activo corriente, centrado en créditos a clientes, consecuencia, probablemente, de una política comercial más agresiva y arbitraria, con el fin de aumentar las ventas. Se intensifica la ineficiencia económica, 1año antes de la quiebra, mientras continúa la escasa generación de recursos que afecta negativamente a la cobertura de las deudas e indica menor solvencia.

Desde el punto de vista práctico, el método Altman puede tener aplicación en entornos donde se necesitan análisis previos para tomar decisiones que tienen implicaciones económicas. Estos ámbitos son los siguientes (Altman, 1968):

1. Evaluación de créditos a empresas. El método Altman permite disponer de un dispositivo rápido y eficaz para detectar un riesgo desfavorable en un préstamo y permite a la entidad bancaria evitar tomar una decisión potencialmente errónea. 
2. Control interno. Para permitir a la dirección de una empresa darse cuenta a tiempo de la gravedad de la situación y predecir los problemas internos de forma temprana.

3. Criterios de inversión. Puede ser una técnica de evaluación para detectar inversiones que no sean convenientes. Teniendo en cuenta que el método es predictivo, un analista de inversiones puede recomendar inversiones más adecuadas o carteras de valores de empresas con buenas previsiones.

Un aspecto a tener en cuenta al poner en práctica el método Altman es que su estudio está basado en grandes empresas de producción y ello deberá ser tenido en cuenta en su aplicabilidad en empresas pequeñas y medianas y de sectores diversos. En nuestro caso, el sector hotelero, será uno de estos sectores diversos.

Siguiendo este mismo criterio, en el siguiente modelo, analizaremos su aplicación al sector hotelero.Se trata del modelo deAmat et al. (2017), la fórmula de los cuales la denominaremos a partir de ahora fórmula $\mathrm{Z}_{\mathrm{AMR}}$, por la abreviación de Amat, Manini y Renart; los 3 autores del referido trabajo. Estos autores realizan un estudio en el que muestran el desarrollo y el examen de un modelo de clasificación para ayudar a las entidades financieras en la valoración de las peticiones de crédito. A través de la aplicación de técnicas estadísticas, el modelo de valoración de crédito ha sido probado con efectividad ya que discrimina las empresas que podrán hacer frente a las deudas contraídas y las que no serán capaces. Los autores presentan la fórmula $\mathrm{Z}_{\mathrm{AMR}}$ basada en una muestra de empresas españolas del año 2008 saneadas y empresas con problemas, teniendo en cuenta empresas manufactureras, comerciales y de servicios de varios tamaños de España:

$\mathrm{Z}_{\mathrm{AMR}}=-3,9+1,28$ (Activo corriente / Pasivo corriente) $+6,1$ (Patrimonio neto / Activo $)+6,5$ (Beneficio neto / Activo $)+4,8$ (Beneficio neto / Patrimonio neto)

Una vez realizados los cálculos, si el valor es $>0$ indica que la empresa tiene una alta probabilidad de tener una buena situación económico-financiera. En cambio, si el valor es $<0$, la probabilidad de insolvencia de la empresa es muy alta.

\section{Tabla 1}

\section{RATIOS PROMEDIO CON ALTO PODER PREDICTIVO}

\begin{tabular}{|l|c|c|}
\hline \multicolumn{1}{|c|}{ RATIO } & EMP. INSOLVENTES & EMP. SOLVENTES \\
\hline Activo corriente / Pasivo corriente & 1,2 & 1,42 \\
\hline Patrimonio neto / Activo & 0,3 & 0,4 \\
\hline Beneficio Neto / Activo & 0,01 & 0,05 \\
\hline Beneficio Neto / Patrimonio neto & 0,03 & 0,07 \\
\hline Fórmula $Z_{\text {AMR }}$ & $-0,325$ & 1,0186 \\
\hline
\end{tabular}

Fuente:Elaboración propia a partir Amat et al. (2017).

Oriol Amat et al. (2017) también realizan un análisis de los ratios que ayudan a discriminar a las compañías solventes de las insolventes. De los 40 ratios que se identifican 
en la mayoría de la literatura que revisaron, finalmente concretaron 4 ratios considerados como de alto poder discriminatorio entre empresas solventes e insolventes, tal como se observa en la tabla 1.

Se debe añadir que Amat et al. (2017) realizan dos modelos de prueba para comprobar la utilidad de la fórmula $\mathrm{Z}_{\mathrm{AMR}}$ propuesta por dichos autores. En el primer test se analizan un total de 2.000 créditos a corto plazo concedidos por un banco, de los cuales 144 acabaron siendo insolventes y representaban el 7,2\% del total de los créditos. Los autores concluyen que si la entidad bancaria hubiera utilizado la fórmula $\mathrm{Z}_{\mathrm{AMR}}$ sólo habría concedido 1.747 créditos ya que el resto habrían sido rechazados o se les hubiera podido solicitar un interés más alto para contrarrestar el mayor riesgo que exigía la operación. Todo ello nos indica que se hubieran rechazado un $12,65 \%$ de los créditos, siendo 5,45 puntos más que los que realmente acabaron en insolvencia.

La segunda prueba fue realizada aplicando la fórmula $\mathrm{Z}_{\mathrm{AmR}}$ en 7 compañías de sectores diferentes (una compañía textil, dos aerolíneas, dos cadenas de centros comerciales, una TV comercial y una empresa inmobiliaria) y usando datos financieros del año 2008. De las 7 empresas, tres de ellas entre el año 2009 y el 2010, presentaron situación de quiebra, mostrando la fórmula $\mathrm{Z}_{\mathrm{AMR}}$ resultados negativos. En cambio, las 4 restantes, siguieron operando con normalidad en el año 2016. Los resultados de estas últimas alcanzaron resultados entre 1 y 8 , confirmando que cifras por encima de 0 avalan la fórmula $Z_{\mathrm{Amr}}$.

Amat et al. (2017) concluyen que en la clasificación de los créditos en las instituciones financieras la predicción de la insolvencia es una herramienta que genera un interés creciente desde hace mucho tiempo. Asimismo, la fórmula $\mathrm{Z}_{\mathrm{AmR}}$ propuesta por los autores puede ser utilizada para evitar problemas de fracasos empresariales ya que la validez de ésta ha sido contrastada con 2 pruebas que muestran su alto poder predictivo, basándose en los 4 ratios analizados.

Para finalizar este apartado, solo añadir que para llegar a las fórmulas Z descritas los autores han realizado completos estudios estadísticos utilizando metodologías como el MDA antes mencionado, ANN (Artificial Neuronal Network), UA (UnivariateAnalysis), etc. Detallamos a continuación, en la tabla 2, un resumen, no exhaustivo, de las principales metodologías y tipos de industrias dónde se han aplicado estudios de Bankruptcydesde la década de los sesenta del siglo pasado.

Tabla 2

METODOLOGÍAS DE LOS ESTUDIOS DE BANKRUPTCY

\begin{tabular}{|l|l|l|l|}
\hline \multicolumn{1}{|c|}{ País } & \multicolumn{1}{c|}{ Tipo de industria } & \multicolumn{1}{c|}{ Año } & \multicolumn{1}{c|}{ Metodología } \\
\hline Australia & Crédito, varias & $1984-2001$ & MDA, ANN \\
\hline Canadá & Manufacturera & 1981 & MDA \\
\hline China & Hotelera, sin especificar & $2006-2007-2009-2017$ & $\begin{array}{l}\text { SVM, CBR, ANN, } \\
\text { MDA, MSM }\end{array}$ \\
\hline
\end{tabular}




\begin{tabular}{|c|c|c|c|}
\hline País & Tipo de industria & Año & Metodología \\
\hline España & $\begin{array}{l}\text { Banca, construcción, } \\
\text { instituciones financieras, } \\
\text { PYME, seguros, varias }\end{array}$ & $\begin{array}{l}\text { 1998-1997-2001-2004- } \\
\text { 2009-2011-2013-2014- } \\
2015-2016-2017\end{array}$ & $\begin{array}{l}\text { SVM, LRA, MDA, } \\
\text { HM, DM, SPSS, MVA, } \\
\text { LDA, probit }\end{array}$ \\
\hline Estados Unidos & $\begin{array}{l}\text { Banca, manufacturera, } \\
\text { restauración, retail, varias }\end{array}$ & $\begin{array}{l}\text { 1966-1968-1977-1980- } \\
1984-1985-1985-1987- \\
1990-1997-2001-2002- \\
2004-2005-2006-2010- \\
2012-2017\end{array}$ & $\begin{array}{l}\text { MDA, ANN, UA, } \\
\text { LRA, RPA, DT, probit, } \\
\text { GA, HM }\end{array}$ \\
\hline Finlandia & Manufacturera, varias & 1991-1992-1993 & MDA, LPM \\
\hline Francia & Manufacturera, textil & 1974-1977-1982-1984 & MDA \\
\hline Grecia & Manufacturera, textil & $\begin{array}{l}\text { 1984-1987-1991-1992- } \\
1993-1994\end{array}$ & $\begin{array}{l}\text { LRA, probit, LPM, } \\
\text { MDA }\end{array}$ \\
\hline Inglaterra & Banca, manufacturera, varias & $\begin{array}{l}\text { 1983-1986-1987-1990- } \\
2001\end{array}$ & LRA, MDA, ANN \\
\hline Italia & Manufacturera & 1984-1991 & MDA \\
\hline Japón & Sin especificar, varias & 1984,2017 & MDA, DHM, \\
\hline Corea & Hotelera, varias & $\begin{array}{l}\text { 1990-1991-1993-1996- } \\
2000-2005-2006-2010- \\
2011\end{array}$ & $\begin{array}{l}\text { MDA, ANN, LRA, } \\
\text { SVM, GA, LRM }\end{array}$ \\
\hline Nueva Zelanda & Varias & 2003 & MDA \\
\hline Suecia & Manufacturera, minería & 1990 & Probit \\
\hline Taiwán & Banca & $2007-2008$ & $\begin{array}{l}\text { MDA, ANN, SVM, } \\
\text { GA }\end{array}$ \\
\hline Turquía & Banca & 2008 & $\begin{array}{l}\text { MDA, CA, SVM, DT, } \\
\text { SVM, ANN }\end{array}$ \\
\hline
\end{tabular}

Nota: ANN, Artificial Neural Network; CA, Cluster Analysis; CBR, Case-Based Reasoning; DHM, Discrete Hazard Model; DM, Data Mining; DT, Decision Tree; ES, Expert System; GA, Genetic Algorithm; HD, Hazard Model; LDA,Linear Discriminant Analysis; LPM, Linear Probability Model; LRA, Logistic Regression Analysis; MDA, Multivariate Discriminant Analysis; MSM, Mixed Sample Modelling; MVA, Multivariate Analysis Variance; Probit, Regression; RPA, Recursive Partitioning Algorithm; SA, Survival Analysis; SPSS, Statistical Package Social Sciences; SVM, Support Vector Machine; UA, Univariate Analysis.

Fuente:Elaboración propia a partir de Kim (2011). 


\section{METODOLOGÍA}

\subsection{Identificación de palabras clave y criterios de búsqueda}

Los criterios de la estrategia de búsqueda marcados en SABI, teniendo en cuenta las opciones que nos ofrece la misma base de datos para la obtención de las empresas en concurso, han sido los siguientes:

- Criterio 1: Todas las empresas.

- Criterio 2: España,empresas en suspensión de pagos y enconcurso de acreedores.

- Criterio 3: CNAE 2009, 5510, hoteles y alojamientos similares.

En los resultados de la búsqueda en SABI (2018) nos muestra que el total de empresas españolas activas registradas ascienden a 1.609.244, de las cuales,12.978, son empresas hoteleras. En referencia a las empresas en suspensión de pagos y en concurso en el sector hotelero, ascienden a 56, según los datos de SABIdesde el año 2006hasta el 2017.

Cabe añadir que esta información puede variar a lo largo del tiempo porque la base de datos se va actualizando periódicamente el criterio "Estado" que se obtiene directamente de los juzgados y se hace de forma independiente a la actualización de las cuentas anuales.

Las palabras clave introducidas en SCOPUS yque hemos utilizado para las búsquedas en la revisión de literatura relacionada han sido las siguientes: Fracaso empresarial, concurso de acreedores, fórmula Z, sector hotelero, predicción del fracaso empresarial. Estos son los términos que consideramos que tienen más relación con las empresas que se encuentran en dificultades y pueden definir mejor el estado de una empresa con problemas financieros.

En cuanto a la información obtenida del INE, el presente trabajoestablece su inicio en el año 2007 y llega hasta el año 2017. Ello nos ha permitido incluir todo el periodo de laúltima crisis económicay los primeros años de la recuperación, que aún continúa consolidándose en los diferentes ámbitos de la economía de nuestro país.

\section{RESULTADOS}

En este apartado, se detallan los resultados obtenidos siguiendo un análisis cuantitativo y otro cualitativo, detallando la evolución de las empresas totales y hoteleras en concurso de acreedores, en liquidación y extinción en España.

\subsection{Análisis cuantitativo}

En la tabla 3 se exponen los resultados de la búsqueda obtenidos por los diferentes medios descritos anteriormente, recalcando que existe una disparidad de resultados dependiendo de la fuente, en función de silos datos provienen del INE o de SABI. Como se puede observar en la misma tabla la actividad económica de hostelería, tiene poca importancia en el total de las sociedades mercantiles en procedimiento concursal en España, representando sólo el 6,40\% en el 2016, siendo este dato el del año con mayor incidencia. 
En la misma tabla se detallan las empresas que se encuentran en proceso concursal según la actividad económica y nos permite hacer una comparación desde el inicio del 2007 hasta el 2017.Podemos observar que las actividades económicas que tienen más empresas concursadas son, en primer lugar, la industria y energía, en segundo lugar, la construcción y, en tercera posición, el comercio. El resto de las actividades económicas tienen una incidencia más baja en comparación con las tres ya mencionadas anteriormente.

\section{Tabla3}

\section{SOCIEDADES MERCANTILES EN PROCEDIMIENTO CONCURSAL Y POR ACTIVIDAD ECONÓMICA EN ESPAÑA}

\begin{tabular}{|c|c|c|c|c|c|c|c|c|c|c|c|c|c|c|c|c|c|c|c|c|c|c|}
\hline \multicolumn{23}{|c|}{ EMPRESAS EN PROCESO CONCURSAL POR ACTIVIDAD ECONÓMICA } \\
\hline ACTIVIDAD ECONÓMICA & 2.007 & $\%$ & 2.008 & $\%$ & 2.009 & $\%$ & 2010 & $\%$ & 2.011 & $\%$ & 2.012 & $\%$ & 2013 & $\%$ & 2.014 & $\%$ & 2.015 & $\%$ & 2.016 & $\%$ & 2.017 & $\%$ \\
\hline TOTAL & 1.033 & 100 & 2.894 & 100 & 5.175 & 100 & 4.990 & 100 & 5.910 & 100 & 8.095 & 100 & 9.143 & 100 & 6.564 & 100 & 5.097 & 100 & 4.080 & 100 & 4.095 & 100 \\
\hline Agricultura y pesca & 21 & 2,03 & 38 & 1,31 & 47 & 0,91 & 53 & 1,06 & 64 & 1,08 & 71 & 0,88 & 83 & 0,91 & 57 & 0,87 & 70 & 1,37 & 39 & 0,96 & 50 & 1,22 \\
\hline Industria y energía & 324 & 31,36 & 664 & 22,94 & 1.245 & 24,06 & 1.013 & 20,30 & 1.125 & 19,04 & 1.531 & 18,91 & 1.575 & 17,23 & 1.023 & 15,59 & 642 & 12,60 & 496 & 12,16 & 541 & 13,21 \\
\hline Construcción & 256 & 24,78 & 1.064 & 36,77 & 1.733 & 33,49 & 1.599 & 32,04 & 1.914 & 32,39 & 2.487 & 30,72 & 2.430 & 26,58 & 1.511 & 23,02 & 1.031 & 20,23 & 739 & 18,11 & 630 & 15,38 \\
\hline Comercio & 204 & 19,75 & 444 & 15,34 & 891 & 17,22 & 816 & 16,35 & 1.049 & 17,75 & 1.505 & 18,59 & 1.687 & 18,45 & 1.272 & 19,38 & 1.100 & 21,58 & 856 & 20,98 & 876 & 21,39 \\
\hline Transporte y almacenamiento & 31 & 3,00 & 99 & 3,42 & 195 & 3,77 & 243 & 4,87 & 265 & 4,48 & 362 & 4,47 & 316 & 3,46 & 253 & 3,85 & 172 & 3,37 & 138 & 3,38 & 164 & 4,00 \\
\hline Hosteleria & 30 & 2,90 & 69 & 2,38 & 104 & 2,01 & 165 & 3,31 & 188 & 3,18 & 277 & 3,42 & 400 & 4,37 & 369 & 5,62 & 302 & 5,93 & 261 & 6,40 & 227 & 5,54 \\
\hline Información y comunicaciones & 24 & 2,32 & 42 & 1,45 & 72 & 1,39 & 86 & 1,72 & 100 & 1,69 & 152 & 1,88 & 217 & 2,37 & 210 & 3,20 & 187 & 3,67 & 133 & 3,26 & 167 & 4,08 \\
\hline Inmobiliarias financieras y seguros & 30 & 2,90 & 130 & 4,49 & 135 & 2,61 & 171 & 3,43 & 189 & 3,20 & 268 & 3,31 & 373 & 4,08 & 253 & 3,85 & 172 & 3,37 & 166 & 4,07 & 147 & 3,59 \\
\hline $\begin{array}{l}\text { Actividades profesionales, científicas } \\
\text { y técnicas }\end{array}$ & 31 & 3,00 & 118 & 4,08 & 185 & 3,57 & 219 & 4,39 & 263 & 4,45 & 355 & 4,39 & 573 & $6,27 \mid$ & 425 & 6,47 & 390 & 7,65 & 335 & 8,21 & 334 & 8,16 \\
\hline $\begin{array}{l}\text { Actividades administrativas y } \\
\text { servicios auxiliares }\end{array}$ & 29 & 2,81 & 72 & 2,49 & 152 & 2,94 & 162 & 3,25 & 192 & 3,25 & 287 & 3,55 & 455 & 4,98 & 284 & 4,33 & 222 & 4,36 & 216 & 5,29 & 205 & 5,01 \\
\hline Resto servicios & 41 & 3,97 & 84 & 2,90 & 137 & 2,65 & 177 & 3,55 & 189 & 3,20 & 302 & 3,73 & 360 & 3,94 & 340 & 5,18 & 319 & 6,26 & 301 & 7,38 & 327 & 7,99 \\
\hline Sin clasificar & 12 & 1,16 & 70 & 2,42 & 279 & 5,39 & 286 & 5,73 & 372 & 6,29 & 498 & 6,15 & 674 & 7,37 & 567 & 8,64 & 490 & 9,61 & 400 & 9,80 & 427 & 10,43 \\
\hline
\end{tabular}

Fuente: Elaboración propia a partir de los datos del INE.

Por lo que se refiere a la evolución de la población de empresas concursadas de la actividad de hostelería en España en el período analizado, podemos ver en la figura 1 que tomando el año 2007 como base, se produce un incremento espectacular del 1.233,33\% deempresas concursadas alcanzando el máximo de toda la serie en el año 2013, con 400 empresas que representaban el 4,37\% del total de empresas de dicho año. Remarcar que, en cualquier caso, a pesar de estas cifras, las empresas del sector hostelero no han tenido, como antes mencionábamos,un granpeso específico como sí lo han tenido la construcción, la industria o el comercio. 


\section{Figura 1 \\ EVOLUCIÓN DE LA POBLACIÓN DE EMPRESAS CONCURSADAS DE LA ACTIVIDAD DE HOSTELERÍA EN ESPAÑA (2007-2017)}

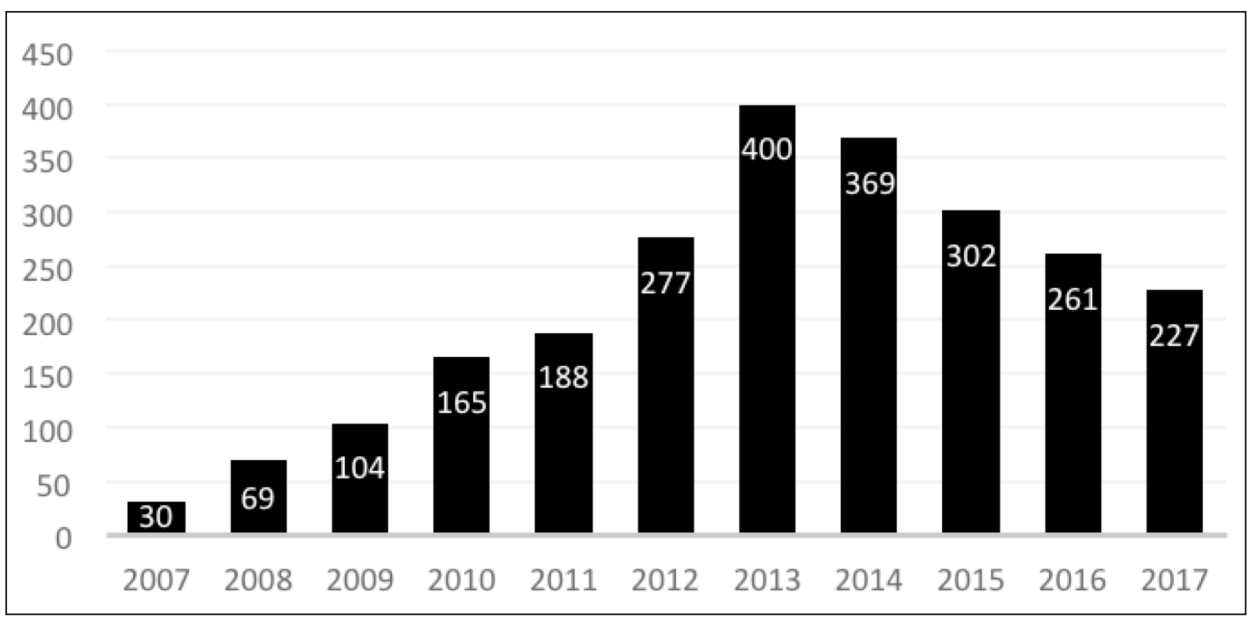

Fuente: Elaboración propia a partir de datos del INE.

Veamos a continuación, en la figura 2, la evolución de la población de las sociedades mercantiles en España, incluyendo las empresas hoteleras. En la misma podemos observar diferentes informaciones relevantes. La primera es la forma del gráfico en forma de V de las empresas activas, donde se ve claramente el descenso de la actividad económica que se inicia en el año 2007 y finaliza en el 2013, destruyéndose un total de 302.929 empresas. El mismo año, el 2013, es el punto de inflexión en el que se produce el inicio de la recuperación económica y, hasta el 2017, último año de este estudio, se habían constituido un total de 218.336 nuevas empresas. Cabe comentar que pasados 10 años del inicio de la crisis el número de empresas activas no se ha igualado con las que había en el 2007, año con mayor actividad económica, siendo las del 2017 similares a las del año 2006, donde existían activas un total de 3.336.657.

La segunda aportación de la figura 2, hace referencia a la evolución de las empresas disueltas. Siguen caminos invertidos a las activas, mientras éstas decrecían en número, las disueltas se incrementan hasta el punto álgido del 2013, iniciándose el descenso a partir del mismo año, pero con un matiz, en los dos últimos años, 2016 y 2017, donde se ha producido un cambio de tendencia y vuelven a incrementarse el número de empresas disueltas. Este cambio de tendencia necesitará un seguimiento minucioso para poder concluir si la recuperación económica sigue adelante y se consolida o, en caso contrario, el incremento de empresas disueltas puede considerarse como predictor de nuevas crisis. Esta afirmación se hace en base a que el año antes del inicio de la crisis, es decir, el año 2006, se pasó de 11.071 empresas disueltas a 18.047 en el año 2007, lo cual representa un incremento del $63 \%$ en un solo año (INE). 


\section{Figura 2 \\ EVOLUCIÓN DE LA POBLACIÓN DE EMPRESAS Y DE LAS SOCIEDADES MERCANTILES DISUELTAS EN ESPAÑA (2007-2017)}

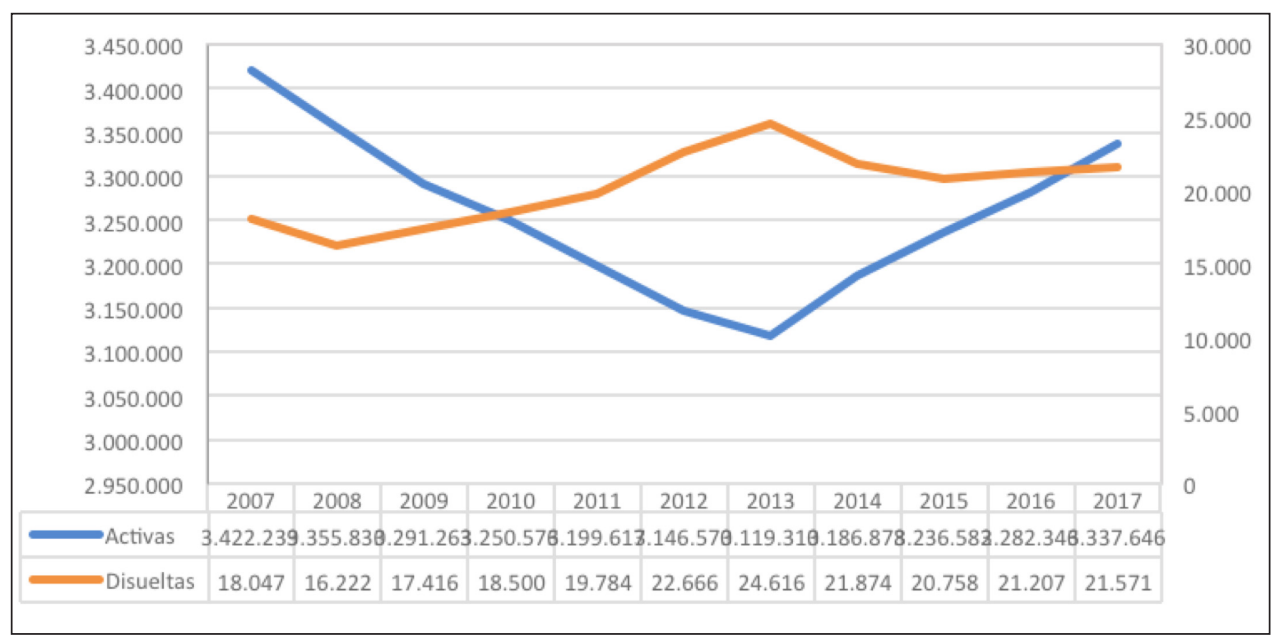

Fuente: Elaboración propia a partir de datos del INE.

En la figura 3 queda reflejada la evolución de las empresas concursadas y disueltas, las cuales siguen una progresión similar, casi paralela, pero siempre con una diferencia considerable en cuanto al número de empresas. Las empresas disueltas se han incrementado en un $19,52 \%$ entre los años 2007 y 2017, en cambio las empresas concursadas han crecido un $77,29 \%$, manteniéndose en unos niveles muy altos. El porqué del alto crecimiento de las concursadas se debe al efecto directo de la crisis y por las modificaciones de la Ley Concursal en los años 2014 y 2015.

En la figura 3 podemos ver como las empresas concursadas y las disueltas siguen caminos más o menos paralelos en el periodo analizado en este estudio. Los aspectos más destacados los encontramos en los puntos máximos de concursos y disoluciones, los cuales difieren en un año entre ellos, siendo para las concursadas el 2012 y para las disueltas el 2013. A partir de ahí, los dos tipos de sociedades describen una caída muy suave con una tendencia muy ligera a volver a subir. También podemos observar que el punto de partida de ambos tipos de sociedades entre el 2007 y el 2008 no ha sido el mismo, mientras las concursadas crecen un $38,7 \%$ en ese mismo año, las disueltas tienen una caída del 10,11\% respecto al 2007. 
Figura 3

EVOLUCIÓN DE LAS SOCIEDADES MERCANTILES CONCURSADAS Y DISUELTAS EN ESPAÑA (2007-2017)

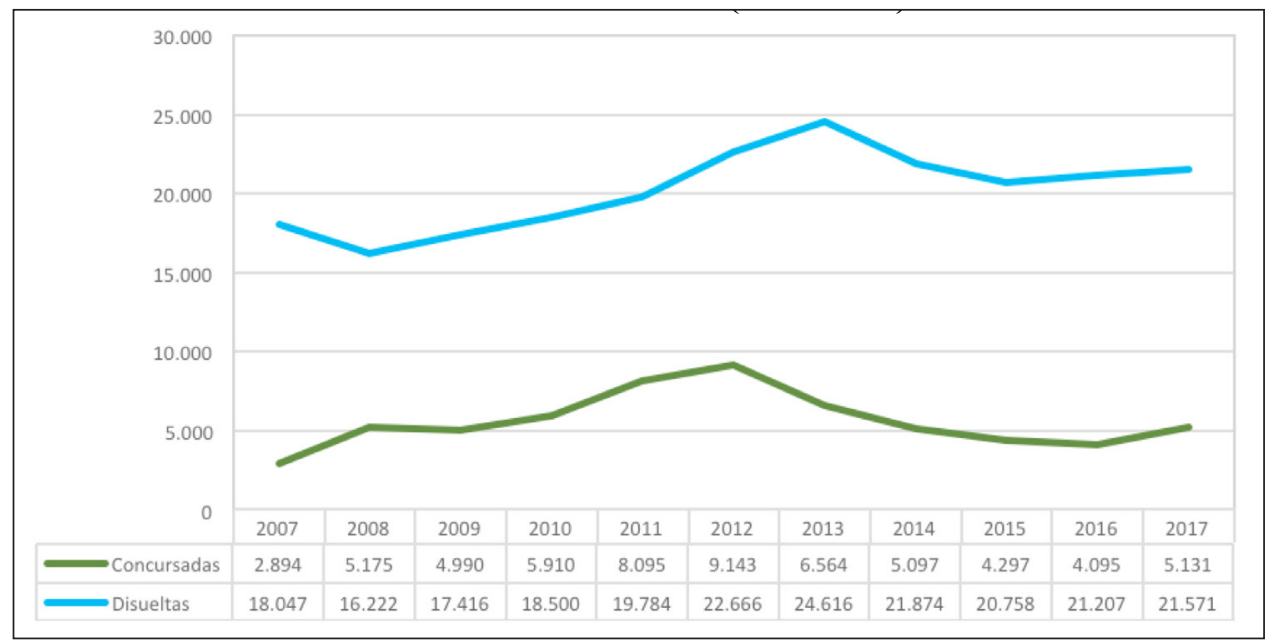

Fuente:Elaboración propia a partir de datos del INE.

Para reflejar la diferencia existente entre los datos de SABI y del INE, tal y como se ha manifestado con anterioridad, se ha elaborado la tabla 4donde se han recopilado las empresas hoteleras y las empresas concursadas totales en España en el periodo 2007-2017.

\section{Tabla4}

\section{EMPRESAS HOTELERASY SOCIEDADES MERCANTILES TOTALES EN PROCEDIMIENTO CONCURSAL (INE-SABI)}

\begin{tabular}{|c|c|c|c|c|c|c|c|c|c|c|c|}
\cline { 2 - 13 } \multicolumn{1}{c|}{} & 2007 & 2008 & 2009 & 2010 & 2011 & 2012 & 2013 & 2014 & 2015 & 2016 & 2017 \\
\hline INE & 2.894 & 5.175 & 4.990 & 5.910 & 8.095 & 9.143 & 6.564 & 5.097 & 4.080 & 4.095 & 5.131 \\
\hline SABI & 241 & 181 & 253 & 371 & 463 & 517 & 606 & 494 & 664 & 1.054 & 563 \\
\hline$\%$ & 8,3 & 3,4 & 5,1 & 6,3 & 5,7 & 5,7 & 9,2 & 9,7 & 16,3 & 25,7 & 10,9 \\
\hline
\end{tabular}

\begin{tabular}{|l|l|l|l|l|l|l|l|l|l|l|l|}
\hline HOTELERAS & 2 & 1 & 1 & 6 & 3 & 8 & 5 & 6 & 5 & 11 & 6 \\
\hline
\end{tabular}

Fuente: Elaboración propia a partir de los datos del SABI e INE

Dicha tabla, nos permite observar que la diferencia existente entre las dos bases de datos, una oficial como es el INE, y la otra, SABI, pone de manifiesto la necesidad de que se establezcan criterios que puedan uniformizar la información recogida en ambas. Con respecto a las empresas hoteleras en el mismo periodo, las hoteleras concursados 
quedan reflejados en la misma tabla 4 y serán los utilizados para aplicar las fórmulas Z descritas anteriormente.

Tabla 5

EMPRESAS DE TODOS LOS SECTORES Y SECTOR HOTELERO EN LIQUIDACIÓN / DISOLUCIÓN Y EN PROCESO CONCURSAL EN ESPAÑA

\begin{tabular}{|l|c|c|c|c|c|c|c|c|c|c|c|c|c|c|c|c|c|c|c|c|c|c|c|c|}
\hline & 2.000 & 2.001 & 2.002 & 2.003 & 2.004 & 2.005 & 2.006 & 2.007 & 2.008 & 2.009 & 2.010 & 2.011 & 2.012 & 2.013 & 2.014 & 2.015 & 2.016 & 2.017 & TOTAL \\
\hline $\begin{array}{c}\text { LQUIDACIÓN / DISOLUCIÓN } \\
\text { TODOS LOS SECTORES }\end{array}$ & 7.282 & 7.318 & 13.011 & 16.930 & 15.733 & 15.014 & 16.328 & 19.184 & 16.776 & 21.716 & 18.540 & 18.604 & 18.561 & 16.297 & 14.812 & 14.521 & 12.159 & 2.462 & 265.248 \\
\hline $\begin{array}{c}\text { CONCURSO ACREEDORES } \\
\text { TODOS LOS SECTORES }\end{array}$ & 48 & 30 & 34 & 56 & 51 & 55 & 128 & 241 & 181 & 253 & 371 & 463 & 517 & 606 & 494 & 664 & 1.054 & 563 & 5.809 \\
\hline $\begin{array}{c}\text { LQUIDACIÓN/ DISOLUCIÓN } \\
\text { SECTOR HOTELERO }\end{array}$ & 59 & 42 & 78 & 81 & 106 & 82 & 108 & 108 & 89 & 125 & 130 & 119 & 96 & 103 & 100 & 93 & 68 & 48 & 1.635 \\
\hline $\begin{array}{c}\text { CONCURSO ACREEDORES } \\
\text { SECTOR HOTELERO }\end{array}$ & & & & & & & 2 & 2 & 1 & 1 & 6 & 3 & 8 & 5 & 6 & 5 & 11 & 6 & 56 \\
\hline
\end{tabular}

Fuente: Elaboración propia a partir de los datos de SABI de 2018.

En la tabla 5 se pueden ver los resultados obtenidos de la búsqueda realizada y en la que se ha separado el sector hotelero del resto de sectores, lo cual nos permite visualizar la evolución del número de empresas que desde el año 2000 se encontraban en suspensión de pagos y a partir del 2003, con la nueva Ley Concursal, pasaron a estar en concurso de acreedores, las empresas en disolución y las empresas en liquidación.

El incremento de las empresas concursadas se mantuvo más o menos estable hasta el año 2005, pero a partir del 2006 y 2007, como si fuera la antesala de la crisis económica que se avecinaba, se produce una aceleración en el número de empresas concursadas, con crecimientos tan espectacularescomo sucede entre los años 2015 y 2016.Se pasa de 664 empresas a 1.054, representando un crecimiento del 59\% en tan solo un año.

También podemos observar como en el sector hotelero la crisis no ha tenido una repercusión tan acusada como en el sector de la construcción o en el de la industria. Debe tenerse en cuenta que el sector hotelero aporta el 11,7\%al PIB nacional, según los resultados registrados en 2017 (INE, 2018). En un ejercicio, entre 2016 y 2017, se eleva la aportación del sector turístico en $0,4 \%$ respecto al año anterior, al tiempo que se suman ya 8 años, desde 2010, con un crecimiento del sector turístico superior al del conjunto de la economía española.

Hay que mencionar que el total de empresas de todos los sectores en España en el periodo 2000-2017 que se encontraban en situación de disolución o liquidación ascendieron a 265.248, de las cuales 5.809 correspondieron a empresas en concurso de acreedores $(2,19 \%)$. En contraposición a estas cifras, las empresas hoteleras en situación de disolución o liquidación fueron 1.635 en el mismo periodo, encontrándose en concurso de acreedores $56(3,43 \%)$. 


\section{Tabla 6 \\ ESTADO DETALLADO DEL TIPO DE DISOLUCIÓN, EXTINCIÓN Y LIQUI- DACIÓN DE LAS EMPRESAS HOTELERAS (2000 - 2017)}

\begin{tabular}{lr}
\hline Disolución: La empresa se encuentra en situación de disolución de pleno derecho. & 1 \\
Disolución: La empresa se encuentra en situación de disolución judicial. & 33 \\
Disolución: La empresa se encuentra en situación de disolución por cesión global de & 1 \\
activo y pasivo. & 97 \\
Disolución: La empresa se encuentra en situación de disolución por otras causas. & 83 \\
Disolución: La empresa se encuentra en situación de disolución voluntaria. & 1 \\
Disolución: La empresa se encuentra en situación de disolución. & 17 \\
Extinción: La empresa se encuentra en situación de extinción por escisión total. & 200 \\
Extinción: La empresa se encuentra en situación de extinción por fusión por & 1 \\
absorción. & 1.030 \\
Extinción: La empresa se encuentra en situación de extinción por fusión por unión. & $\mathbf{7 1}$ \\
Extinción: La empresa se encuentra en situación de extinción. & 100 \\
Liquidación concursal: La empresa se encuentra en situación de liquidación & 1.635 \\
concursal judicial. & \\
Sin descripción & \\
Total general &
\end{tabular}

Fuente: Elaboración propia a partir de los datos de SABI.

La tabla 6amplía información sobre los motivos por los que las empresas fueron liquidadas o disueltas en el sector hotelero. Se observa que 71 empresas hoteleras del total de 1.635 se encuentran en situación de liquidación concursal judicial.El resto se reparten entre empresas que se encuentra en situación de disolución de pleno derecho, disolución judicial, de disolución por cesión global de activo y pasivo, disolución voluntaria o disolución por otras causas. En el mismo grupo de clasificación, tenemos empresas que se encuentran en situación de extinción por escisión total, extinción por fusión por absorción y extinción por fusión por unión.

También nos muestra que el motivo principal de la disolución de las empresas hoteleras en España es por otras causas no determinadas en 97 empresasy la disolución se produce de forma voluntaria en 83 de las empresas.

Otro aspecto importante es la duración del proceso concursal. A efectos de contabilizar dichotiempo, se consideracomo inicio de este el último año disponible de sus cuentas, ya que, a partir del siguiente ejercicio,y hasta que formalmente se establece un pronunciamiento concursal, pueden pasar varios años. Esta afirmación se desprende de la información encontrada en SABI en el apartado "detalles de la empresa" donde se ha observado que las empresas concursadas pasan entre 1año y 6 años hasta su disolución. Altman et al. (2017),describen en su artículo que,dado que las bases de datos no facilitan la fecha de quiebra, utilizan la fecha del último año disponible antes de que ésta se produzca, por lo 
que este criterio también se ha seguido homogéneamente en el presente trabajo. En el caso de SABI aparece la fecha de la resolución judicial indicando que la empresa se encuentra en proceso concursal, pero ésta pocas veces coincide con el último año del depósito de cuentas y que, como ya hemos dicho, puede variar de 1 a 6 años.

Esta observación obtenida de SABI queda reforzada y contrastada si tenemos en cuenta la tabla 7, en la que nos muestran los años de origen de los concursos que concluyen el año 2017. Sólo el 25,9\% de los concursos provienen del mismo 2017.El resto se reparte en diferentes ejercicios hasta el año de origen 2010, con un relevante 5,2\% del total. Esto significa que los procesos concursales pueden durar de 1 a 7 años, prácticamente el mismo resultado obtenido de SABI, de 1 a 6 años.

\section{Tabla 7 \\ AÑOS DE DURACIÓN DEL CONCURSO DE ACREEDORES}

CONCURSOS LIQUIDATORIOS INICIADOS EN $2010 \mathrm{Y}$

EN AÑOS POSTERIORES QUE CONCLUYEN EN 2017

\begin{tabular}{ccc} 
AÑO & NÚMERO & PORCENTAJE \\
\hline 2017 & 995 & 25,9 \\
2016 & 312 & 8,1 \\
2015 & 448 & 11,7 \\
2014 & 513 & 13,4 \\
2013 & 625 & 16,3 \\
2012 & 454 & 11,8 \\
2011 & 293 & 7,6 \\
2010 & 198 & 5,2 \\
\hline Total & 3.838 & 100,0 \\
\hline
\end{tabular}

Fuente: Colegio de Registradores de la Propiedad y Mercantiles de España.

\subsection{Análisis cualitativo}

Para establecer el análisis cualitativoseguiremos teniendo en cuenta que el ámbito geográficode estudio es España y por lo que se refiere a las variables que se aplicarán en el estudio de las empresas concursadas del sector hotelero, las utilizadas en el presente trabajo de las dos fórmulas Z son en el caso de Altman (1968-1983) la liquidez, la rentabilidad, el apalancamiento y la solvencia.En el caso de Amat et al. (2017) la liquidez (Activo corriente / Pasivo corriente), la solvencia (Patrimonio neto / Activo), la rentabilidad sobre activos (Beneficio Neto / Activo) y la rentabilidadsobre el patrimonio neto(Beneficio Neto / Patrimonio neto).

En la década de los noventa en España diferentes autores concluyeron que las variables más destacadas de predicción en el sector asegurador son la liquidez y la rotación (Rodríguez, 1990), la rentabilidad y la liquidez (López y Rodríguez, 1994; Mora, 1994). En la predicción de crisis de las pymes la rentabilidad, la liquidez, tamaño y sector (López et al., 
1998), la rentabilidad, la liquidez y el endeudamiento a 1 año (Gallego et al., 1997) y, por último, la rentabilidad y el endeudamiento mixtos (Lizárraga, 1997; Fernando y Blanco, 1998). Los autores que han hecho esta recopilación de estudios de este periodo, Laffarga y Mora (2002), también concluyen que la rentabilidad y la liquidez son las variables más relacionadas con la futura insolvencia de la empresa.

\subsection{Aplicación fórmulas $\mathrm{Z}_{1}, \mathrm{Z}_{2}, \mathrm{Z}_{3}$ y $\mathrm{Z}_{\mathrm{AMR}}$}

A continuación, se muestra cómo se ha realizado el análisis de las 45 empresas hoteleras en concurso de acreedores y que, a modo de ejemplo,se presenta en la tabla 10. En todos los casos se ha aplicado las fórmulas propuestas y, el resultado permitiría al directivo, al analista financiero, al accionista o al posible inversor de la empresa tener una primera aproximación de cuál es la situación de la misma.

ZANONA, S.A. es una empresa ubicada en Cádiz y constituida en el año 1985, cuyaactividad principal es la explotación de hoteles, con una plantilla de 145 trabajadores en el último año de actividad y un activo valorado en 58,74 M€. Se puede observar como la empresa concursada tiene los 5 ejercicios previos al concurso con beneficio netonegativo, lo cual ya pone de manifiesto que la probabilidad de quiebra es alta. Haciendo un primer análisis del año-5, se observa que el pasivo corriente es 4 veces más alto que el activo corriente, lo cual significa que la empresa podía tener dificultades para hacer frente a las obligaciones a corto plazo. También se aprecia que las ventas han sido bajas, lo que debería llevar a realizar un análisis de esta situación para intentar mejorarla. Otro dato que manifiesta síntoma negativo es el BAII que en los 5 ejercicios ha sido negativo. Todo ello ayudará al analista que, siguiendo la información, ejercicio por ejercicio, pueda interpretar los motivos que han llevado a la empresa a la situación concursal y posteriormente a su liquidación o cierre definitivo.

Finalmente, podemos apreciar que, en este caso concreto, las 4 fórmulas, $Z_{1}, Z_{2}, Z_{3}$ y $Z_{\mathrm{AMR}}$, han acertado en un alto porcentaje la posibilidad de quebrar la empresa hotelera analizada ya que reflejan la probabilidad alta de quiebra con los resultados obtenidos en los 5 ejercicios previos a la declaración oficial de concurso de acreedores. Las diferencias en la aproximación en el acierto de una fórmula o de la otra se debe a que cada autor les ha dado más importancia a unas variables que a otras, siempre según los resultados obtenidos en sus investigaciones previas a la obtención de las fórmulas Z.

Acontinuación se detalla en las figuras 4,5, 6 y 7los resultados de la aplicación de las fórmulas $\mathrm{Z}_{1}, \mathrm{Z}_{2}, \mathrm{Z}_{3}$ y $\mathrm{Z}_{\mathrm{AmR}}$ a las 45 empresas seleccionadas de las 56 concursadas del sector hotelero.Dichas empresas se encontraban en concurso de acreedores en España en el periodo que se inicia en el año 2000 y concluye en el 2017 (ver tabla 5). Las once empresas que se han descartado ha sido como consecuencia de no disponer de los datos que permitieran realizar los cálculos necesarios. 


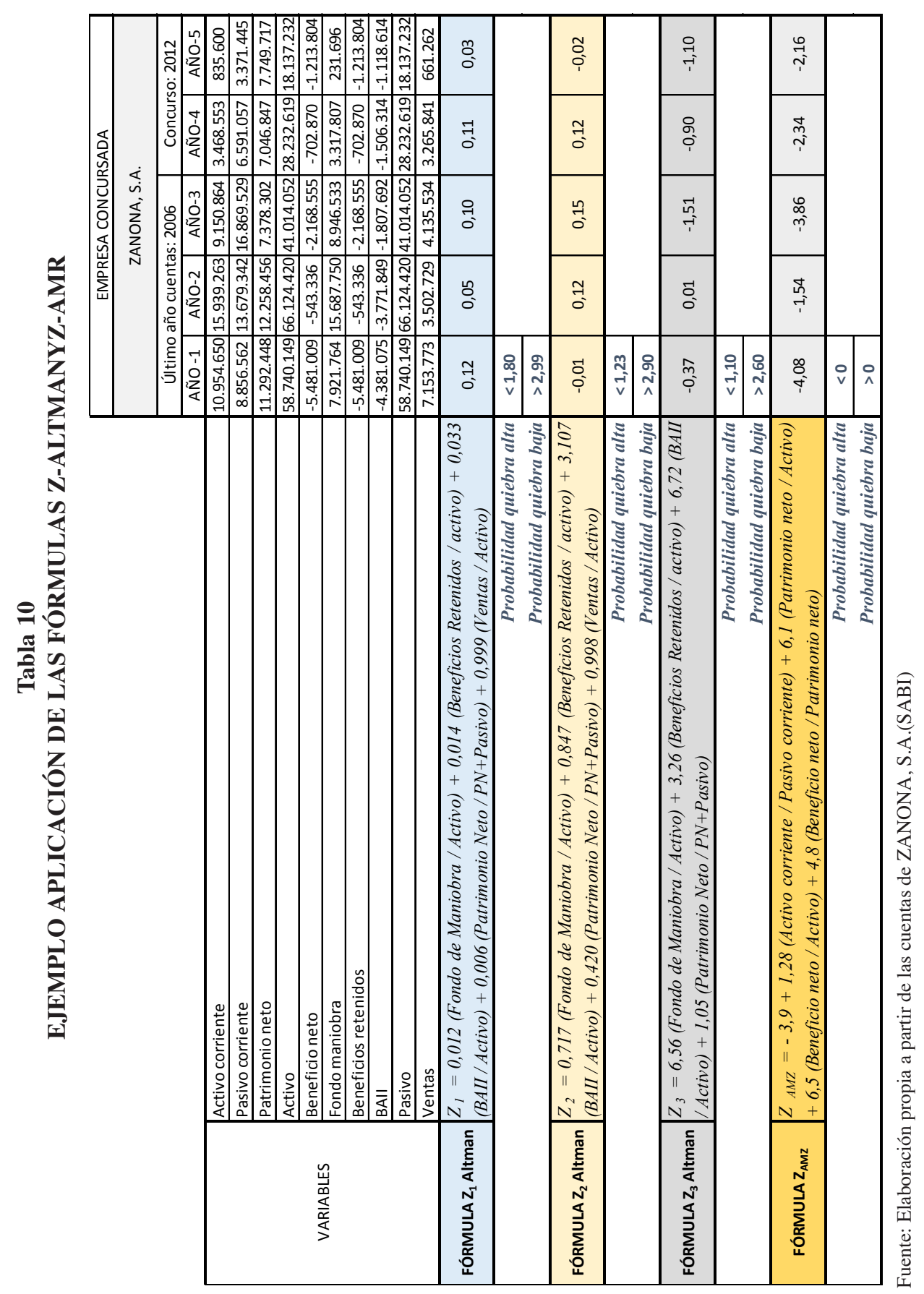


Figuras 4 y 5

PORCENTAJE DE APROXIMACIÓNDE LA FÓRMULA $\mathrm{Z}_{1} \mathrm{yZ}_{2}$
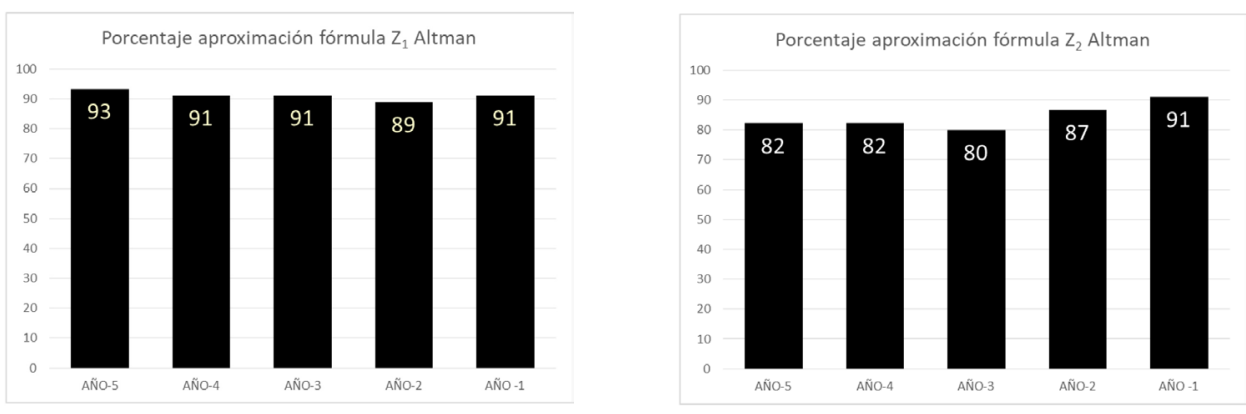

Fuente: Elaboración propia a partir de los datos de $\mathrm{SABI}$ y las fórmulas $\mathrm{Z}_{1}, \mathrm{Z}_{2}, \mathrm{Z}_{3}$ y $\mathrm{Z}_{\mathrm{AmR}}$.

Figuras 6 y 7

PORCENTAJE DE APROXIMACIÓN DE LA FÓRMULA $Z_{3}$ y $Z_{\text {AMR }}$
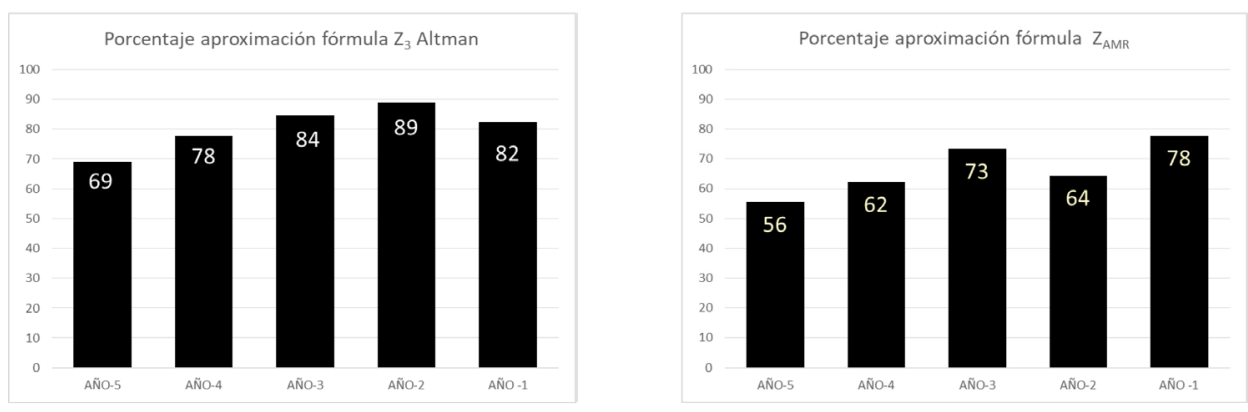

Fuente: Elaboración propia a partir de los datos de $\mathrm{SABI}$ y las fórmulas $\mathrm{Z}_{1}, \mathrm{Z}_{2}, \mathrm{Z}_{3}$ y $\mathrm{Z}_{\mathrm{AMR}}$.

De las empresas hoteleras concursadas en España el porcentaje de aproximación de las 4 fórmulas esen el año-1 del $91 \%$ de $\mathrm{Z}_{1}$ y $\mathrm{Z}_{2}$, del $82 \%$ de la $\mathrm{Z}_{3}$ y del $78 \%$ de $\mathrm{Z}_{\mathrm{AmR}}$, lo que nos lleva a manifestar que, en este caso, se aproximan máspara el sector hotelerolas fórmulas de Altman en sus 3 versiones. Por lo tanto, la que tiene un mayor porcentaje de acierto es la fórmula de Z-Altman de $1968\left(\mathrm{Z}_{1}\right)$ que el resto de las fórmulas del mismo autor o que la fórmula $Z_{\mathrm{AMR}}$ de 2017 en los 5 ejercicios analizados de las empresas en concurso.

Los resultados obtenidos en nuestro estudio comparado con las fórmulas $\mathrm{Z}$ de Altman y la $\mathrm{Z}_{\mathrm{AMR}}$, son los siguientes:

1. Utilizando los datos financieros previos al concurso, la fórmula $\mathrm{Z}_{1}$ obtuvo unaaproximación de un $95 \%$ del total de las empresas que se declararon en concurso. En nuestro estudio hemos obtenido unaaproximación del 91,1\%, del 91,1\%, del $82,2 \%$ con Z-Altman y un $77,8 \%$ con $\mathrm{Z}_{\mathrm{AmR}}$.

2. El $65 \%$ de las 66 empresas analizadas presentan pérdidas en los 3 años previos en la aplicación fórmula $Z_{1}$. En nuestro análisis de las 45 empresas del sector hotelero, 
en el año-1 el 64\% de las empresas presentan pérdidas, en el año-2, el 58\% y en el año-3, el 53\%.

3. La predicción a largo plazo, según Altman, no ofrece resultados aceptables y deja constancia en su trabajo que a partir del tercer año la predicción baja por debajo del 50\%. Los resultados obtenidos en nuestro estudio muestran que las fórmulasZ de Altman en el sector hotelero se han mantenido por encima del $80 \%$ y superando el $90 \%$ en las $Z_{1}$ i $Z_{2}$. En cambio, con la fórmula $Z_{\mathrm{AMR}}$, vemos que la predicción siempre nos marca resultados por debajo del $80 \%$, llegando al $56 \%$ en el año-5.

\section{DISCUSIÓN}

En este apartado se ponen de manifiesto los gaps detectados, así como las futuras líneas de investigación propuestas tras el trabajo realizado.

\subsection{Gaps detectados}

\subsubsection{El tiempo de resolución de los procesos concursales.}

Uno de los aspectos más relevantes en la resolución de los procesos concursales en España es el tiempo transcurrido bajodicha situación y la importancia que tiene la duración del proceso concursal para la salvación o no de la empresa sea del sector hotelero o no, tal y como queda reflejado en los análisis expuestos.

\subsubsection{La diferencia en el número de empresas concursadas y empresas disueltas.}

Sería conveniente realizar una evaluación global de la utilidad de la Ley Concursal ya que hay más empresas disueltas que concursadas y, posiblemente, sea un síntoma de que iniciar un proceso concursal no resulta fácil para muchas empresas que se encuentran en estado de insolvencia.Con toda certeza, la gran diferencia existente entre concursadas y disueltas se deba al tamaño. Las microempresas, de 1 a 9 trabajadores, representan el 68\% de las empresas disueltas, según datos del INE, y, por otro lado, las empresas entre 10 y 49 trabajadores son el $17 \%$ del total de disueltas. Si agrupamos estos datos nos encontramos que el $85 \%$ de las empresas disueltas corresponden a microempresas y pequeñas empresas que, normalmente, son las que tienen más dificultades para obtener recursos financieros en el caso de encontrarse con problemas de viabilidad.El sector hotelero tiene una proporción similar, el $86 \%$ de las empresas son microempresas o pequeñas empresas según los datos del INE (2018) pero con una diferencia, las microempresas son el $12 \%$ y las pequeñas son el $74 \%$ de las empresas hoteleras.

5.1.3. El incremento de las empresas disueltas el año previo al inicio de la crisis como predicción de esta.

Como ya se ha comentado en el apartado 4.1 de este mismo trabajo, el incremento de empresas disueltas podría considerarse como un predictor de nuevas crisis. En esta línea,Álvarez-Ferrer y Campa-Planas (2018), indican que antes del inicio de la crisis del 
año 2007, el INE registró un incremento del $63 \%$ en un solo año de las empresas que se disolvieron, en concreto entre el 2006 y 2007.En la última consulta realizada en el INE, los datos oficiales del octubre del 2018 indican que se ha producido un incremento acumulado anual del 10,1\% de las empresas disueltas. Esta aseveración deberá ser confirmada en el momento en que se produzca un nuevo ciclo de crisis económica.

\subsection{Futuras líneas de investigación}

Una primera línea de investigación podríaorientarse en analizar la duración de los procesos concursales de las empresas hoteleras, y su impacto ante la continuidad o no de una empresa concursada, teniendo en cuenta que cuanto más tiempo transcurra, más probabilidades existen de concluir en disolución.

La segunda línea de investigación podría centrarse en encontrar una explicación de por qué las empresas disueltas son 4,2 veces más que las concursadas en el año 2017, por ejemplo, como puede observarse de la figura 3 y si el sector hotelero sigue la misma proporción que el resto de las empresas.

Una tercera línea de investigación podría considerar el análisis del incremento de empresas disueltas que se produce el año anterior a la declaración oficial de la crisis yanalizar si se puede considerar como predictor de nuevas crisis. Plantearse un futuro estudio del comportamiento que se produce en las empresas en las vísperas de las crisis ayudaría a confirmar, o no,las sospechas de estar ante una nueva crisis económica.

\section{CONCLUSIONES}

Una de las prioridades del presente trabajose ha basadoen hacer una aportación a la comunidad científica sobre la predicción del fracaso empresarial en el sector hotelero. Así mismo, se ha podido comprobar la poca existencia de literatura previa sobre la quiebra hotelera en el contexto español, siendo este uno de los motivos que justifican la realización del presente trabajo.

Como han concluido algunos autores analizados, las empresas en quiebra presentan un menor tamaño y poca antigüedad, valores más bajos de rentabilidad, liquidez, actividad y porcentaje de fondos propios sobre activo corriente. Además, tienen valores más altos en las variables de endeudamiento y porcentaje de activo corriente sobre el activo total. La probabilidad de quiebra en laspymes hoteleras mantiene una relación positiva con el endeudamiento y la estructura económica, y negativa con la rentabilidad, la actividad, la antigüedad y el tamaño. Las empresas que obtienen una mejor rentabilidadno están tan expuestas a una posible situación concursal, en cambio, elevados endeudamientos incrementan la posibilidad de quebrar al no ser capaces de hacer frente a las obligaciones de pago. En resumen, las variables que tienen una mayor incidencia en las empresas hoteleras en la quiebra son una escasa o negativa rentabilidad, un alto nivel de endeudamiento, poca capacidad de autofinanciación y escasa o nula generación de recursos.

También podemos concluir que la duración de los procesos concursales tiene una importancia relevante. Ha quedado contrastado mediante SABI y los datos aportados en el Anuario Concursal 2017 del Colegio de Registradores de la Propiedad y Mercantiles 
de España que la duración de dichos procesos concursales puede llegar a durar hasta 7 años. Este periodo de tiempo puede ser letal para la continuidad de las empresas y más si tenemos en cuenta que la longevidad de las mismas tiene una relación directa en su supervivencia, pues aproximadamente el $50 \%$ de las empresas activas tienen una antigüedad de 5 años o menos, por lo que si se acogen al proceso concursal y se alarga demasiado en el tiempo no será posible corregir los problemas que han llevado al concurso a la misma.

Para la siguiente conclusión mencionar que el $18 \%$ de los concursos son considerados, de entrada, económicamente inviables. Sólo el 7,48\% de las empresas concursadas concluyen con éxito su proceso y, además, el 92,52\% de empresas acaban en liquidación después de pasar entre uno y siete años, tal y como se ha descrito en el párrafo anterior. Si atendemos al estudio realizado, de las 56 empresas hoteleras en concurso en España, únicamente 4 continúan activas, lo que significa que tan solo un 7,14\% del total de las empresas concursadas del sector hotelero han conseguido enderezar el rumbo de la empresa y, posiblemente, gracias al concurso de acreedores, hayan podido continuar su actividad económica y empresarial. Si comparamos este resultado con lo manifestado por Almazor (2015) nos pone de relieve unos resultados similares con nuestro estudio. Un 7,48\% de las empresas concursadas concluyen con éxito su proceso, según dicho autor,mientras que el 7,14\% corresponde al resultado delpresente estudio.

El objetivo principal de este estudio ha sido comprobar si las principales fórmulas que se proponen para predecir la insolvencia son capaces de detectar la insolvencia empresarial de las empresas del sector hotelero en España y, concretamente, en base a las que, oficialmente, según SABI, estaban en concurso de acreedores. Pues bien, la conclusión es que las fórmulas $Z_{1}$ y $Z_{2}$ de Altman tienen un mayor alto poder predictivo para detectar la situación de quiebra de forma anticipada que las fórmulas $\mathrm{Z}_{3}$ de Altman y $\mathrm{Z}_{\mathrm{AmR}}$ de Amat et al.

La fórmula $Z_{1}$ de Altman permite predecir entre 1 y 5 años previos a la situación concursal, por lo que se puede afirmar que es una buena herramienta de predicción para las empresas del sector hotelero tal y como se ha analizado con las 45 empresas hoteleras. La aplicación de la fórmula $Z_{1}$ de Altman en el sector hotelero, desde un punto de vista práctico, puede ayudar en la toma de decisiones empresariales porque delante de situaciones en las que son necesarios análisis previos para afrontar las mismas, puede permitir a una empresa hotelera mejorar sus procesos de toma de decisiones.

\section{BIBLIOGRAFÍA}

ALMAZOR, E. VAN H. (2015): Estadística Concursal. Anuario 2015. Colegio de Registradores.

ALTMAN, E.I. (1968): "Financial Ratios, Discriminant Analysis and the Prediction of Corporate Bankruptcy," Journal of Finance, vol. 23 (4), pp. 589-609.

ALTMAN, E.I. (1983): Corporate financial distress: A complete guide to predicting, avoiding, and dealing with bankruptcy. New York, John Wiley \& Sons.

ALTMAN, E.I, IWANICZ-DROZDOWSKA, M., LAITINEN, K.E. y SUVAS, A. (2017):

"Financial Distress Prediction in an International Context: A Review and Empirical Analysis of Altman's Z-Score Model”. Journal of International Financial Management \& Accounting, vol. 28 (2), pp. 131-171. 
ÁLVAREZ-FERRER, A. y CAMPA-PLANAS F. (2018): “Evolución y análisis de las empresas concursadas en España en el período 2009-2016", Revista Iberoamericana de Contabilidad de Gestión, vol. XVI (31), pp. 1-14.

AMAT, O., MANINI, R. y RENART, M.A. (2017): "Credit Concession through credit scoring: Analysis and application proposal”. Intangible Capital, vol. 13 (1), pp. 51-70.

BEAVER, W. (1966): "Financial ratios as prediction of failure. Empirical Research in Accounting: Selected Studies." Journal of Accounting Research, vol. 4, pp. 71-111.

BOE (2018). https://www.boe.es/buscar/pdf/2003/BOE-A-2003-13813-consolidado.pdf. Fecha del último acceso: Marzo, 2019.

DIAKOMIHALIS, M. (2012): “The accuracy of Altman's models in predicting hotel bankruptcy", International Journal of Accounting and Financial Reporting, vol. 2 (2), pp.96-113.

ELSEVIER (2018): https://www.elsevier.com/solutions/scopus.Consulta realizada el julio de 2018.

FERNANDO, M. y BLANCO, F. (1998): "La previsión del fracaso empresarial en la comunidad valenciana: aplicación de los modelos discriminante y logit", Revista Española de Financiación y Contabilidad, n ${ }^{\circ}$ 95, pp. 499-540.

GALLEGO, A.M., GÓMEZ, J.C. y YÁÑEZ, L. (1997): "Modelos de predicción de quiebras en empresas no financieras", Actualidad Financiera, vol. 2 (5), pp. 3-14.

GARCÍA MARÍ, J.H., SÁNCHEZ VIDAL, F.J. y TOMASETI SOLANO, E. (2018): "Características de las empresas y del gobierno corporativo de los Administradores concursales como factores determinantes del éxito del proceso concursal". Ponencia. XVIII Encuentro Internacional AECA, Lisboa.https://aeca.es/wp-content/uploads /2014/05/145b.pdf.

GAZENGEL, A. y THOMAS, P. (1992): "Les défaillancesd'entreprises". Cahiers de Recherche, núm. 92-105, EcoleSuperieure de Commerce de Paris.

GONZÁlEZ, A.L., CORREA, A., ACOSTA, M. y BARRIOS, I. (2004): "La inestabilidad de los modelos de predicción del fracaso empresarial". Comunicación en las $V$ Jornadas AECA. Universidad de Oviedo.

GU, Z. y GAO, L. (2000):“A multivariate model for predicting business failures of hospitality firms", Henry Stewart Publications: Tourism and Hospitality Research, vol. 2 (1), pp. 37-49.

INE (2019): http://www.ine.es/prodyser/pubweb/anuario18/anu18_09finan.pdf .Fecha del último acceso: Julio 2019.

JAWABRECH, O., AL RAWASHDEH, F. y SENJELAWI, O. (2017):“Using Altman's Z-Score model to predict the financial failure of hospitality companies-case of Jordan". International Journal of Information, Business and Management, vol. 9 (2), p. 141.

KIM, S.Y. (2011): "Prediction of hotel bankruptcy using support vector machine, artificialneural network, logistic regression, and multivariate discriminant analysis", The Service Industries Journal, vol. 31 (3), pp. 441-468.

LAFFARGA, J. y MORA, A. (2002): "La predicción del fracaso empresarial. Es estado de la cuestión en España”. Comunicación en las V Jornadas AECA. Universidad de Oviedo. 
LIZÁRRAGA, F. (1997): "Utilidad de la información contable en el proceso de fracaso: análisis del sector industrial de la mediana empresa española", Revista Española de Financiación y Contabilidad, $\mathrm{n}^{\circ}$ 92, pp. 873-915.

LÓPEZ, D., MORENO, J. y RODRÍGUEZ, P. (1994): "Modelos de Previsión del Fracaso Empresarial: Aplicación a Entidades de Seguros en España", Esic Market, n 84, pp. $83-125$.

LÓPEZ, J., GANDÍA, J.L. y MOLINA, R. (1998): "La suspensión de pagos en las Pymes: una aproximación empírica", Revista Española de Financiación y Contabilidad, ${ }^{\circ}$ 94, pp. 71-97.

MORA ENGUÍDANOS, A. (1994): "Los modelos de Predicción del Fracaso Empresarial: Una aplicación del Logit", Revista Española de Financiación y Contabilidad, ${ }^{\circ}$ 78, pp. 203-233.

MUÑOZ-IZQUIERDO, N., CAMACHO-MIÑANO, M.M. y PASCUAL-EZEMA, D. (2017): "Contenido del informe de auditoría en el año previo a la declaración del concurso de acreedores. Contraste empírico para el caso español", Revista Española de Financiación y Contabilidad, vol. 46 (1), pp. 92-126.

REGISTRADORES DE ESPAÑA. Fecha del último acceso: Junio, 2019. http://www.registradores.org/wpcontent/estadisticas/mercantil/concursal/Anuario_Concursal_2017.pdf

RODRIGUEZ, M.C. (1990): La Predicción de las Crisis Empresariales. Modelos para el Sector de Seguros. Valladolid, Universidad de Valladolid.

SABI (2018): https://sabi-bvdinfo-com.sabidi.urv.cat/home.serv?product=sabineo\&loginf romcont ext=ipaddress. Fecha del último acceso: Marzo, 2019.

SCOPUS (2018): Disponible online en: http://www.scopus.com. Fecha del último acceso:Mayo, 2019.

VARGAS, J.A. (2015): “Modelos de Beaver, Ohlson y Altman: ¿Son capaces de predecir la bancarrota en el sector empresarial costarricense?", Tec Empresarial, vol. 8 (3), pp. 29-40.

VIVEL-BÚA, M., LADO-SESTAYO, R. y OTERO-GONZÁLEZ, L. (2015): “¿Por qué quiebran los hoteles españoles?: un estudio de sus determinantes", Tourism \& Management Studies, vol. 11 (2), pp. 25-30. 
